\title{
Formation of weed community in pea (Pisum sativum L.) as affected by herbicide and crop rotation
}

\section{Kształtowanie się zbiorowisk chwastów grochu siewnego (Pisum sativum L.) pod wpływem herbicydu i następstwa roślin}

\author{
Bogumił Rychcik*, Milena Kaźmierczak, Marzena Michalska, Helena Bepirszcz
}

\begin{abstract}
Summary
This paper presents the results obtained in the crop rotation experiment carried out in the years 2008-2010. It concerns weed infestation of pea (Venus variety) cultivated in six-field crop rotation: sugar beet - maize - spring barley - pea - winter oilseed rape winter wheat, and in monoculture since 1993. Two levels of crop protection were compared: level $0-$ no chemical protection, and $\mathrm{H}-$ with the protection of herbicide (linuron) applied after sowing at $1.5 \mathrm{~kg} / \mathrm{ha}$ doses. The species composition and the number of weeds were determined at the development stage of 2-4 leaves of pea and prior to the mechanical cultivation using a frame with an area of $0.25 \mathrm{~m}^{2}$. On the objects without chemical protection in crop rotation and in monoculture the number of weeds amounted to 237 plants $/ \mathrm{m}^{2}$ and 614 plants $/ \mathrm{m}^{2}$, respectively. The applied herbicide reduced the number of weeds in the crop rotation by $87.8 \%$ and by $82.5 \%$ in the monoculture. Regardless of the chosen method of crop protection, the following weed species dominated: Chenopodium album, Thlaspi arvense and Capsella bursa-pastoris. In monocultural cultivation Lycopsis arvensis, Polygonum convolvulus and also perennial weeds occurred as well.
\end{abstract}

Key words: Pisum sativum L.; weeds; herbicide; crop rotation; monoculture

\section{Streszczenie}

Przedstawiono wyniki badań uzyskanych w statycznym doświadczeniu polowym realizowanym w latach 2008-2010. Praca dotyczy zachwaszczenia grochu siewnego (odmiana Wenus) uprawianego w płodozmianie 6-polowym: burak cukrowy - kukurydza - jęczmień jary - groch siewny - rzepak ozimy - pszenica ozima oraz w monokulturze od 1993 roku. Porównywano dwa poziomy ochrony roślin grochu: 0 - bez ochrony chemicznej oraz H - z ochroną herbicydem (linuron) stosowanym bezpośrednio po siewie w dawce 1,5 kg/ha. Skład gatunkowy oraz liczbę chwastów określono w fazie rozwojowej 2-4 liści grochu, przed pielęgnacją mechaniczną, posługując się ramką o powierzchni $0,25 \mathrm{~m}^{2}$. Na obiektach bez ochrony chemicznej liczba chwastów w płodozmianie wyniosła średnio $237 \mathrm{szt} . / \mathrm{m}^{2}$, zaś w monokulturze $-614 \mathrm{szt} . / \mathrm{m}^{2}$. Zastosowany herbicyd zredukował liczbę chwastów w płodozmianie o $87,8 \%$, a w monokulturze o $82,5 \%$. Niezależnie od sposobu ochrony plantacji w płodozmianie dominowały: Chenopodium album, Thlaspi arvense i Capsella bursa-pastoris, natomiast w uprawie monokulturowej oprócz wymienionych występowały: Lycopsis arvensis, Polygonum convolvulus oraz chwasty wieloletnie.

Słowa kluczowe: Pisum sativum L.; chwasty; herbicyd; płodozmian; monokultura 


\section{Wstęp / Introduction}

Groch (Pisum sativum L.) jest jedną z najważniejszych roślin bobowatych (Fabaceae) uprawianych w Polsce, jednak w porównaniu z Niemcami i Francją jego areał jest znikomy i obecnie wynosi 15,4 tys. ha (FAOSTAT 2012). Jest gatunkiem ważnym gospodarczo i przydatnym do uprawy zarówno dla rolnictwa ekologicznego, jak i zrównoważonego. Jednak ze względu na długi okres wschodów oraz powolny początek rozwoju, bardzo łatwo ulega zachwaszczeniu. Groch wprowadzony do zmianowania zbożowego jest postrzegany jako roślina regenerująca stanowisko i dająca korzyści rolniczo-ekonomiczne (Małecka i wsp. 2009). Z badań Borówczaka i wsp. (2008) wynika, że pozytywnym efektem wynikającym $\mathrm{z}$ bezpłużnej uprawy roli dla grochu siewnego jest ograniczenie procesów erozyjnych, liczniejsze zasiedlanie gleby przez dżdżownice, wzbogacone życie mikrobiologiczne gleby, zmniejszona mineralizacja substancji organicznej gleby, poprawione stosunki wodne gleby przez usprawnienie podsiąku kapilarnego oraz ograniczenie parowania $\mathrm{z}$ powierzchni pola. Z kolei w warunkach uprawy bezpłużnej Stupicka-Rodzynkiewicz i wsp. (2004) wykazali wzrost zachwaszczenia plantacji. W celu przeciwdziałania temu zjawisku Fougereus i Dore (1997) wskazują, aby dobierać odpowiednie odmiany grochu, szczególnie wąsolistnego, które są odporniejsze na okresy posuszne i wyleganie. Jak podają Podleśny i wsp. (1993) jest to konieczne ze względu na konkurencję chwastów $\mathrm{z}$ roślinami grochu o wodę, światło i składniki pokarmowe. Chwasty przyczyniają się nie tylko do obniżenia plonu (nawet o 50\%), ale także utrudniają sam zbiór (Borówczak i wsp. 2008). Z badań Szwejkowskiej (2006) dotyczących porównania metod zwalczania chwastów (mechanicznej, mechanicznochemicznej oraz chemicznej) wynika, że najbardziej skutecznym sposobem jest zastosowanie herbicydów, ale są one niewystarczająco skuteczne w niesprzyjających warunkach pogodowych. Ponadto w pracach różnych autorów wykazano, że skuteczność oraz selektywność działania zastosowanych herbicydów zależą od warunków atmosferycznych panujących podczas wykonywania zabiegu, fazy rozwojowej roślin uprawnych i chwastów oraz przedplonu (Stupnicka-Rodzynkiewicz i wsp. 2004; Rychcik 2005; Księżak 2007; Sekutowski i Badowski 2011).

Celem badań było określenie wpływu herbicydu i systemu następstwa roślin na ograniczenie zachwaszczenia plantacji grochu siewnego (odmiana Wenus) uprawianego w płodozmianie i monokulturze.

\section{Materiały i metody / Materials and methods}

W pracy przedstawiono wyniki badań uzyskanych w doświadczeniu płodozmianowym realizowanym w latach 2008-2010, w Zakładzie Produkcyjno-Doświadczalnym Bałcyny koło Ostródy. Statyczny eksperyment polowy, dotyczący wrażliwości roślin na uprawę po sobie, prowadzony był na glebie płowej, klasy bonitacyjnej IIIb-IVa, kompleksu pszennego dobrego i żytniego bardzo dobrego. Praca dotyczy zachwaszczenia grochu siewnego (odmiana Wenus) uprawianego w płodozmianie 6-polowym: burak cukrowy (na oborniku) - kukurydza - jęczmień jary - groch siewny - rzepak ozimy - pszenica ozima oraz w monokulturze od 1993 roku. Stosowano dwa poziomy ochrony roślin grochu: 0 - bez ochrony chemicznej oraz $\mathrm{H}-\mathrm{z}$ ochroną herbicydem Afalon Dyspersyjny 450 SC (substancja czynna - s.cz. - linuron) stosowanym bezpośrednio po siewie w dawce $1,5 \mathrm{~kg} / \mathrm{ha}$.

Uprawę roli pod groch prowadzono systemem płużnym. Obornik w płodozmianie stosowano pod burak cukrowy (30 t/ha), a w monokulturze grochu w $2008 \mathrm{r}$. (15 t/ha), zaś nawozy mineralne w ilości $200 \mathrm{~kg} / \mathrm{ha}$ $(\mathrm{N}-40, \mathrm{P}-60, \mathrm{~K}-100)$ aplikowano przedsiewnie. Norma siewu wynosiła 100 kiełkujących nasion na $1 \mathrm{~m}^{2}$. Skład gatunkowy oraz liczbę chwastów określono corocznie w fazie rozwojowej 2-4 liści grochu przed pielęgnacją mechaniczną posługując się ramką o powierzchni $0,25 \mathrm{~m}^{2}$ na każdym obiekcie w czterech powtórzeniach. Wyniki opracowano statystycznie programem STATISTICA v. 10, $\mathrm{a}$ istotność różnic określono na poziomie $\mathrm{p}=0,05$.

\section{Wyniki i dyskusja / Results and discussion}

W okresie badań 2008-2010, na obiektach bez ochrony chemicznej, w płodozmianie, odnotowano średnio 237 szt. $/ \mathrm{m}^{2}$ chwastów, natomiast w monokulturze $614 \mathrm{szt} . / \mathrm{m}^{2}$. Z kolei na obiektach, gdzie zastosowano herbicyd (s.cz. linuron) stwierdzono odpowiednio 31 i 69 szt. $/ \mathrm{m}^{2}$ chwastów. Niezależnie od systemu następstwa roślin oraz sposobu ograniczania zachwaszczenia najmniejszą ich liczbę odnotowano w 2009 r. (tab. 1, rys. 1). W płodozmianie, na obiekcie bez ochrony chemicznej stwierdzono 23 gatunki chwastów. Wśród chwastów krótkotrwałych dominowały: Chenopodium album - stanowiąc 25,1\%, Capsella bursa-pastoris 11,5\%, Thlaspi arvense - 10,7\%, Viola arvensis - 7,3\%, Matricaria maritima - 7\% i Echinochloa crus-galli -

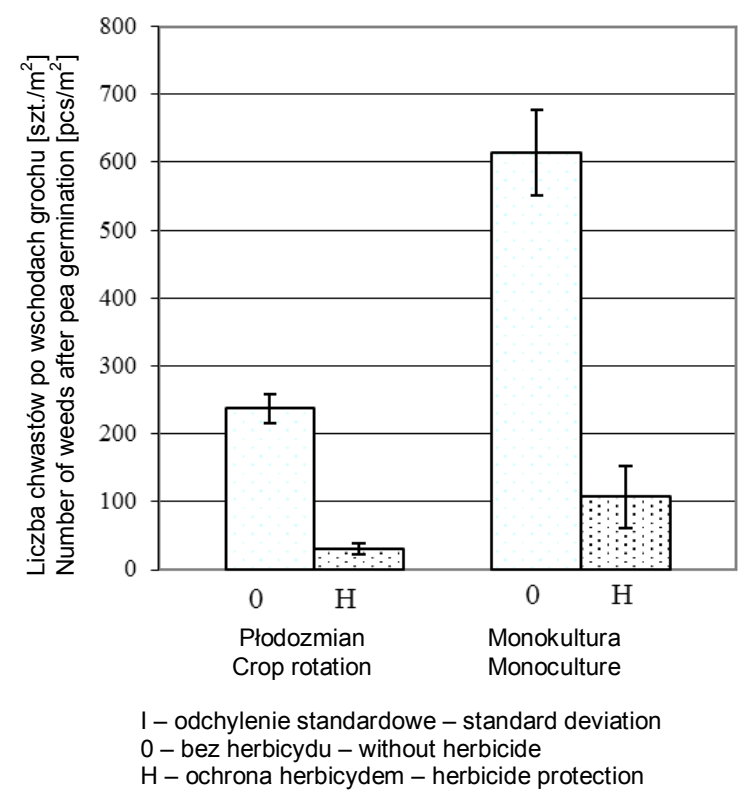

Rys. 1. Liczba chwastów po wschodach grochu [szt. $\left./ \mathrm{m}^{2}\right]$ Fig. 1. Number of weeds after pea germination $\left[\mathrm{pcs} / \mathrm{m}^{2}\right]$ 
Tabela 1. Wiosenne zachwaszczenie grochu siewnego w latach badań $\left[\mathrm{szt} . / \mathrm{m}^{2}\right]$

Table 1. Spring weed infestation of pea in the years of study $\left[\mathrm{pcs} / \mathrm{m}^{2}\right]$

\begin{tabular}{|c|c|c|c|c|}
\hline $\begin{array}{l}\text { Następstwo roślin } \\
\text { Crop sequence }\end{array}$ & $\begin{array}{l}\text { Rok } \\
\text { Year }\end{array}$ & $\begin{array}{c}\text { Bez herbicydu } \\
\text { Without herbicyde }\end{array}$ & $\begin{array}{l}\text { Ochrona herbicydem } \\
\text { Herbicide protection }\end{array}$ & $\begin{array}{c}\text { Średnia } \\
\text { Mean }\end{array}$ \\
\hline \multirow{2}{*}{$\begin{array}{l}\text { Płodozmian } \\
\text { Crop rotation }\end{array}$} & $\begin{array}{l}2008 \\
2009 \\
2010\end{array}$ & $\begin{array}{l}284 \\
194 \\
232 \\
\end{array}$ & $\begin{array}{l}31 \\
49 \\
14\end{array}$ & $\begin{array}{l}157,5 \\
121,5 \\
123,0\end{array}$ \\
\hline & $\begin{array}{c}\text { średnia } \\
\text { mean }\end{array}$ & 236,7 & 31,3 & 133,9 \\
\hline \multirow{2}{*}{$\begin{array}{l}\text { Monokultura } \\
\text { Monoculture }\end{array}$} & $\begin{array}{l}2008 \\
2009 \\
2010 \\
\end{array}$ & $\begin{array}{l}668 \\
496 \\
678 \\
\end{array}$ & $\begin{array}{c}133 \\
128 \\
61\end{array}$ & $\begin{array}{l}400,5 \\
312,0 \\
369,5\end{array}$ \\
\hline & $\begin{array}{c}\text { średnia } \\
\text { mean }\end{array}$ & 614 & 107,3 & 360,7 \\
\hline \multicolumn{2}{|l|}{$\begin{array}{l}\text { Średnia } \\
\text { Mean }\end{array}$} & 425,3 & 69,3 & - \\
\hline $\begin{array}{l}\text { NIR }(0,05) \\
\operatorname{LSD}(0.05) \\
\text { dla }- \text { for: }\end{array}$ & \multicolumn{4}{|c|}{$\begin{array}{l}\text { I) następstwo roślin - crop sequence: } 28,4 \\
\text { II) poziom ochrony roślin }- \text { level of crop protection: } 16,2 \\
\text { III) lata - years: } 25,1 \\
\text { interakcja - interaction: I } \times \text { II }-22,9 \text {; II } \times \text { III }-35,5 \text {; } \times \text { II } \times \text { III }-50,2\end{array}$} \\
\hline
\end{tabular}

Tabela 2. Zbiorowiska chwastów agrocenozy grochu (odmiana Wenus) w zależności od następstwa i ochrony roślin, w latach 2008-2010 $\left[\mathrm{szt} . / \mathrm{m}^{2}\right]$

Table 2. Weed communities in agrocenosis of pea (variety Wenus) influenced by crop rotation and plant protection in the years $2008-2010\left[\mathrm{pcs} / \mathrm{m}^{2}\right]$

\begin{tabular}{|c|c|c|c|c|}
\hline \multirow[b]{2}{*}{$\begin{array}{l}\text { Gatunki chwastów } \\
\text { Weed species }\end{array}$} & \multicolumn{2}{|c|}{ Płodozmian - Crop rotation } & \multicolumn{2}{|c|}{ Monokultura - Monoculture } \\
\hline & $\begin{array}{c}\text { bez herbicydu } \\
\text { without } \\
\text { herbicide }\end{array}$ & $\begin{array}{l}\text { ochrona } \\
\text { herbicydem } \\
\text { herbicide } \\
\text { protection }\end{array}$ & $\begin{array}{l}\text { bez herbicydu } \\
\text { without herbicide }\end{array}$ & $\begin{array}{l}\text { ochrona } \\
\text { herbicydem } \\
\text { herbicide } \\
\text { protection }\end{array}$ \\
\hline Liczba gatunków - Number of species & 23 & 21 & 23 & 21 \\
\hline 1. Krótkotrwałe - Short term & & & & \\
\hline Fiołek polny - Viola arvensis & 17,3 & 3,6 & 8,0 & 1,3 \\
\hline Chaber bławatek-Centaurea cyanus & 2,0 & $<1$ & 0,0 & 0,0 \\
\hline Chwastnica jednostronna - Echinochloa crus-galli & 15,3 & 2,4 & 15,3 & 2,9 \\
\hline Dymnica pospolita - Fumaria officinalis & 2,7 & $<1$ & 2,0 & $<1$ \\
\hline Gorczyca polna - Sinapis arvensis & 4,7 & $<1$ & $<1$ & $<1$ \\
\hline Gwiazdnica pospolita - Stellaria media & 11,3 & 1,6 & 13,3 & 1,6 \\
\hline Jasnota różowa - Lamium amplexicaule & 6,7 & $<1$ & 4,0 & $<1$ \\
\hline Komosa biała - Chenopodium album & 59,3 & 8,2 & 148,7 & 12,7 \\
\hline Maruna bezwonna - Matricaria maritima & 16,7 & 1,3 & 26,7 & 1,1 \\
\hline Niezapominajka polna - Myosotis arvensis & 1,3 & $<1$ & 4,7 & $<1$ \\
\hline Poziewnik szorstki - Galeopsis tetrahit & 1,3 & $<1$ & 1,3 & 0,0 \\
\hline Rdest kolankowaty - Polygonum lapathifolium & 4,7 & $<1$ & 19,3 & 4,0 \\
\hline Rdestówka powojowata - Fallopia convolvulus & 10,0 & 1,6 & 22,0 & 10,0 \\
\hline Rdest ptasi - Polygonum aviculare & 4,0 & $<1$ & 36,0 & 12,9 \\
\hline Sporek polny - Spergula arvensis & 1,3 & 0,0 & 37,3 & 2,9 \\
\hline Tasznik pospolity - Capsella bursa-pastoris & 27,3 & $<1$ & 46,7 & 2,7 \\
\hline Tobołki polne - Thlaspi arvense & 25,3 & 3,3 & 122,0 & 14,2 \\
\hline Wiechlina roczna - Poa annua & 6,0 & $<1$ & 8,0 & $<1$ \\
\hline Przytulia czepna - Galium aparine & 8,7 & 2,9 & 15,3 & 6,9 \\
\hline Krzywoszyj polny - Lycopsis arvensis & 4,0 & $<1$ & 63,3 & 27,8 \\
\hline Iglica pospolita - Erodium cicutarium & 1,3 & 0,0 & 0,0 & 0,0 \\
\hline 2. Wieloletnie - Perennial & & & & \\
\hline Gorczyca polna - Sinapis arvensis & 3,3 & $<1$ & 2,7 & $<1$ \\
\hline Ostrożeń polny - Cirsium arvense & 0,0 & 0,0 & 2,7 & $<1$ \\
\hline Perz właściwy - Elymus repens & 2,0 & $<1$ & 10,7 & 3,6 \\
\hline Skrzyp polny - Equisetum arvense & 0,0 & 0,0 & 3,3 & 0,0 \\
\hline
\end{tabular}


$6,5 \%$, podczas gdy gatunki wieloletnie stanowiły łącznie 4,8\% ich liczby (tab. 2). Na obiektach monokulturowych, również bez herbicydowej ochrony plantacji, liczba zidentyfikowanych gatunków wynosiła -23 . Jednocześnie zaszły istotne zmiany w składzie gatunkowym chwastów. Populacja Ch. album zwiększyła się z 59,3 do 148,7 szt. $/ \mathrm{m}^{2}$, C. bursa-pastoris z 27,3 do $48 \mathrm{szt} . / \mathrm{m}^{2}, T$. arvense z 25,3 do 102 szt. $/ \mathrm{m}^{2}$, M. maritima z 16,7 do $26,7 \mathrm{szt} . / \mathrm{m}^{2}$, stanowiąc odpowiednio $24,2 \%, 19,9 \%, 4,3 \%, 2,5 \%$ liczebności zbiorowisk. Chwasty wieloletnie w monokulturze na obiekcie bez ochrony chemicznej stanowiły 4,5\%, a wśród nich stwierdzono dużą liczebność Elymus repens $-10,7 \mathrm{szt} . / \mathrm{m}^{2}$ i Sonchus arvensis $-2,7 \mathrm{szt} . / \mathrm{m}^{2}$.

Jak podaje Gawrońska-Kulesza (1975) wzrost zachwaszczenia w monokulturze peluszki wpływa na mniejszą powierzchnię liści, słaby rozwój, delikatniejsze łodygi oraz plonowanie roślin. Dominującym gatunkiem w cytowanej pracy była komosa biała. W badaniach przeprowadzonych przez Rychcika (2005) groch uprawiany w monokulturze bez zastosowania herbicydów uległ silnemu zachwaszczeniu przez: Ch. album, T. arvense, V. arvensis, Poa annua, C. bursa-pastoris i $M$. maritima. O możliwości ograniczenia zbiorowisk chwastów oraz zawodności uprawy grochu w monokulturze informowali Wenda-Piesik i Rudnicki (2003). Z kolei w badaniach Urbanowskiego i wsp. (1997), Kurowskiego i wsp. (2002) oraz Małeckiej i wsp. (2009) jednoznacznie stwierdzono, że uprawa grochu w monokulturze prowadzi nie tylko do zachwaszczenia plantacji, lecz także do rozwoju chorób.

Po zastosowaniu herbicydu Afalon Dyspersyjny 450 SC (s.cz. linuron) w płodozmianie zmniejszyła się liczba chwastów do $31 \mathrm{szt} . / \mathrm{m}^{2}$, czyli o $87,8 \%$. Nastąpiły niewielkie zmiany $\mathrm{w}$ procentowych relacjach dominujących gatunków, odnotowano zmniejszenie ich liczby w przypadku C. bursa-pastoris z 11,5 do 2,1\%, a $V$. arvensis zwiększenie $\mathrm{z} 7,3$ do $11,3 \%$. W monokulturze traktowanej herbicydem liczba chwastów zmniejszyła się o $82,5 \%$. Odnotowano 21 gatunków, a dominowały tu: Lycopsis arvensis - 25,9\%, T. arvense - 13,3\%, Polygonum aviculare $-12 \%$ oraz Ch. album - 11,8\%. Gatunki wieloletnie stanowiły $4,8 \%$, wśród nich największy udział stanowił $E$. repens $-3,3 \%$.

Jak podają Gugała i Zarzecka (2011) oraz Sekutowski i Badowski (2011) użyte do pielęgnacji herbicydy zapewniają utrzymanie plantacji grochu siewnego w stanie wolnym od chwastów. Odnotowali także znaczne różnice w działaniu herbicydów w odniesieniu do poszczególnych gatunków chwastów. Z kolei w badaniach przeprowadzanych przez Księżaka (2007) skuteczność działania dla jednego herbicydu wynosiła 90\%, zaś w przypadku zastosowania trzech herbicydów dochodziła do $97 \%$.

\section{Wnioski / Conclusions}

1. Groch siewny uprawiany bez użycia herbicydów, zarówno $\mathrm{w}$ płodozmianie, jak i monokulturze ulegał silnemu zachwaszczeniu przez Ch. album i T. arvense. W płodozmianie w większej liczbie wystąpiły także: C. bursa-pastoris, V. arvensis i E. crus-galli, a w monokulturze: L. arvensis, $P$. aviculare i $M$. maritima.

2. Stosowany corocznie herbicyd Afalon Dyspersyjny 450 SC ograniczał liczebność chwastów w płodozmianie o $87,8 \%$, a w monokulturze o $82,5 \%$.

3. W przypadku chwastów wieloletnich $\mathrm{w}$ płodozmianie występowały $S$. arvensis i E. repens, natomiast w monokulturze dodatkowo $E$. arvense i $C$. arvense.

\section{Literatura / References}

Borówczak F., Rębarz K., Grześ S. 2008. Wpływ deszczowania, technologii uprawy i nawożenia azotem na zachwaszczenie grochu siewnego w trzeciej rotacji czteropolowego płodozmianu. [Influence of irrigation, cultivation technology and nitrogen fertilization on weed infestation of pea in third four field crop rotation]. Progress in Plant Protection/Postępy w Ochronie Roślin 48 (4): $1396-1401$

Fougereus J.A., Dore T. 1997. Water stress during reproductive stages affects see and yield of pea (Pisum sativum L.). Crop Science 37 (4): 1247-1252.

Gawrońska-Kulesza A. 1975. Uprawa peluszki w monokulturze. [Field pea cultivation in monoculture]. Roczniki Nauk Rolniczych Seria A: Produkcja roślinna 100 (4): 105-121.

Gugała M., Zarzecka K. 2011. Regulacja zachwaszczenia w uprawie grochu siewnego odmiany Wiato. [Regulation of weed infestation in pea crop, cultivar Wiato]. Progress in Plant Protection/Postępy w Ochronie Roślin 51 (1): 342-347.

FAOSTAT 2012. http://faostat.fao.org/ [Accessed: 04.08.2014].

Księżak J. 2007. Wpływ wybranych herbicydów na rozwój i plonowanie wąskolistnej odmiany grochu siewnego. [Influence of selected herbicides on development and yielding of semileafless variety of pea]. Progress in Plant Protection/Postępy w Ochronie Roślin 47 (3): 169-172.

Kurowski T.P., Cwalina-Ambroziak B., Sadowski T. 2002. Płodozmian jako czynnik różniący nasilenie chorób grochu polnego (Pisum sativum L.). [Crop rotation as a factor differentiating the intensity of the diseases of field pea (Pisum sativum L.)]. Acta Agrobotanica 55 (1): 173-183.

Małecka I., Blecharczyk A., Dobrzeniecki T. 2009. Produkcyjne i środowiskowe skutki wieloletniego stosowania systemów bezorkowych w uprawie grochu siewnego. [The productivity and environmental consequences of long-term ploughless tillage systems in field pea]. Fragmenta Agronomica 26 (3): 118-127.

Podleśny J., Lenartowicz W., Księżak J. 1993. Przydatność niektórych herbicydów do zwalczania chwastów w zasiewach grochu. [Use of some herbicides to weed control in the sowing pea plants]. Fragmenta Agronomica 10 (3): 177-178.

Rychcik B. 2005. Wpływ herbicydu i następstwa roślin na zachwaszczenie grochu pastewnego (Pisum sativum L.). [Effect of herbicide and crop sequence on weed infestation of pea field (Pisum sativum L.)]. Progress in Plant Protection/Postępy w Ochronie Roślin 45 (2): 1039-1042. 
Sekutowski T., Badowski M. 2011. Wpływ zachwaszczenia oraz ochrony herbicydowej na plonowanie grochu siewnego (Pisum sativum L.). [Effect of weed infestation and herbicide protection on yielding of pea (Pisum sativum L.)]. Progress in Plant Protection/Postępy w Ochronie Roślin 51 (4): 1858-1863.

Stupnicka-Rodzynkiewicz E., Stępnik K., Lepiarczyk A. 2004. Wpływ zmianowania, sposobu uprawy roli i herbicydów na bioróżnorodność zbiorowisk chwastów. [Effect of the crop rotation, tillage method and herbicides on the biodiversity of weed communities]. Acta Scientiarum Polonorum, Agricultura 3 (2): 235-245.

Szwejkowska B. 2006. Reakcja odmian grochu siewnego (Pisum sativum L.) na różne metody zwalczania chwastów. [Reaction of pea (Pisum sativum L.) cultivars to different weed control methods]. Acta Scientiarum Polonorum, Agricultura 5 (1): 71-82.

Urbanowski S., Rajs T., Piekarczyk M. 1997. Produkcyjność grochu pastewnego w zmianowaniu tradycyjnym, uproszczonym i w monokulturze. [Productivity of fodder pea in conventional and simplified crop rotations and in monoculture]. Zeszyty Problemowe Postępów Nauk Rolniczych 446: 161-164.

Wenda-Piesik A., Rudnicki F. 2003. Przydatność mieszanek herbicydowych we współrzędnych uprawach grochu ze zbożami jarymi. [Usefulness of herbicide mixtures on mixed stands of pea and spring cereals]. Zeszyty Problemowe Postępów Nauk Rolniczych 490: 285-291. 